\title{
Validation of the Use of Historical Events to Estimate the Age of Subjects Aged 65 Years and Over in Cotonou (Benin)
}

\author{
Moussiliou Noël Paraïso ${ }^{a, b}$ Dismand Houinato ${ }^{c, d}$ Maëlenn Guerchet ${ }^{a}$ \\ Victoire Aguèh $^{b}$ Philippe Nubukpo ${ }^{a, e, f} \quad$ Pierre-Marie Preux ${ }^{a, g, h}$ \\ Benoît Marin ${ }^{\mathrm{a}} \mathrm{g}, \mathrm{h}$ \\ aUniversité de Limoges, IFR 145 GEIST, Institut d'Epidémiologie Neurologique et de Neurologie Tropicale,

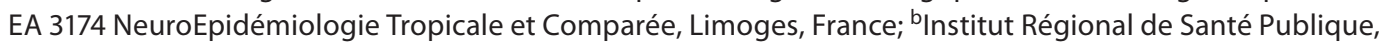 \\ Ouidah; 'Université d'Abomey Calavi, Faculté des Sciences de la Santé, Unité d'Enseignement et de Recherche de \\ Neurologie, and d Département de Neurologie, Hôpital Universitaire, Cotonou, Bénin; ${ }^{\mathrm{C}} \mathrm{CHU}$ Limoges, CH Esquirol,

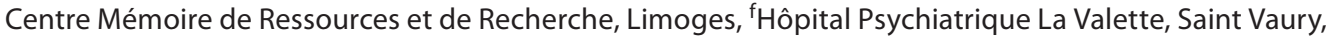 \\ 9CHU Limoges, Service de l'Information Médicale et de l'Evaluation, Unité Fonctionnelle de Recherche Clinique \\ et de Biostatistique, and ' Université de Limoges, Faculté de Médecine, Laboratoire de Biostatistique et \\ d'Informatique Médicale, Limoges, France
}

\section{Key Words}

Epidemiology, Benin · Methods, historical events • Age groups $\cdot$ Date of birth

\begin{abstract}
Background: Our aim was to validate the use of historical events as tools for estimating the age of people $\geq 65$ years in Cotonou (Benin). Methods: The survey was conducted in Cotonou, the economic capital of Benin. We included people aged $\geq 65$ years, with at least a primary education level and an administrative document certifying their date of birth. The historical events were the solar eclipse of 1946 covering the national territory and the date of independence (1st August 1960) of Dahomey (Benin). Agreement between estimated and actual age was assessed by the intraclass correlation coefficient and the Bland and Altman graphical representation. Results: We included 112 subjects. The intraclass correlation coefficient between actual and estimated age by the use of historical landmarks was $0.87(95 \% \mathrm{Cl}=0.81-0.91)$,
\end{abstract}

i.e. an excellent concordance. The graph of Bland and Altman did not demonstrate any systematic error of estimation. Conclusion: The development of similar tools in other parts of Africa and developing countries may improve the quality of information collected in epidemiological studies and thereby enhance the accuracy of the results of studies conducted on age-related disorders such as dementia.

Copyright $\odot 2010$ S. Karger AG, Basel

The determination of the correct age of the population in sub-Saharan African countries is difficult especially for those who are born before independence. Most of these countries have a real deficit of reliable and accessible administrative documentation. This could be related with high illiteracy rates, insufficient number of or distant administrative structures, high rate of at-home births that often goes unreported, as well as lack of awareness and motivation among government agencies and citizens, especially those in rural areas.

\section{KARGER}

Fax +41613061234 E-Mail karger@karger.ch www.karger.com
Pierre-Marie Preux

EA 3174 NeuroEpidémiologie Tropicale et Comparée

Institut d'Epidémiologie Neurologique et de Neurologie Tropicale, Faculté de Médecine

2, rue du Dr. Marcland, FR-87025 Limoges (France)

Tel. +335554358 20, Fax +335554358 21, E-Mail preux@ unilim.fr 
This often introduces an uncertainty in determining the age of persons participating in epidemiological investigations and may therefore cause a selection or information bias limiting the validity of their results.

Out of several tools available for age estimation in epidemiological investigations, the use of historical landmarks seems to be most relevant. Indeed major events leave a deep impression on populations and can easily be remembered. This method has previously been used in Ibadan (Nigeria) [1]. In this earlier study, the use of specific historical events for the concerned region (the 1917 pandemic influenza and the 1925 visit of the Prince of Wales) permits to estimate the age of 59 people aged $40-$ 90 years. The Spearman correlation coefficient between the estimated age and the age in official records was excellent $(r=0.989)$, but the intraclass correlation coefficient (ICC), the appropriate method to quantify the agreement, was not reported.

Currently in Benin (West Africa), there are no official statistics or documents to estimate the proportion of citizens who are unaware of their correct age and who have no official document mentioning their date of birth. Concerned about the lack of proof of age for a majority of the population, the Beninese government has recently launched a campaign 'audience foraine pour l'établissement d'un acte de naissance ou de jugement supplétif' [2]. The aim is to establish and deliver birth certificates for persons who have not got any, in order to correct such lacks of information.

Incidence and prevalence of dementia vary significantly between age groups $[3,4]$. In the methods of our recent study on cognitive impairment and dementia in subjects aged $\geq 65$ years in Benin [5], we decided to use historical events to estimate the age of respondents who have no official documentation to justify their actual age. This study aimed to validate the use of 2 historical landmarks, the solar eclipse of 1946 covering the national territory and the date of independence of Dahomey (Benin) on 1st August 1960, for estimating the age of persons aged $\geq 65$ years in the city of Cotonou.

\section{Materials and Methods}

\section{Study Population and Sampling}

This cross-sectional survey was conducted in May 2008 in Cotonou (Littoral county), the economic capital of Benin. Cotonou covers an area of $79 \mathrm{~km}^{2}$ and is divided into 13 districts and 140 subdistricts. It has a population of 808,018 inhabitants, which represents $9.82 \%$ of the total Benin population. The population density is high: 8,419 inhabitants per $\mathrm{km}^{2}$. Those aged $\geq 65$ years

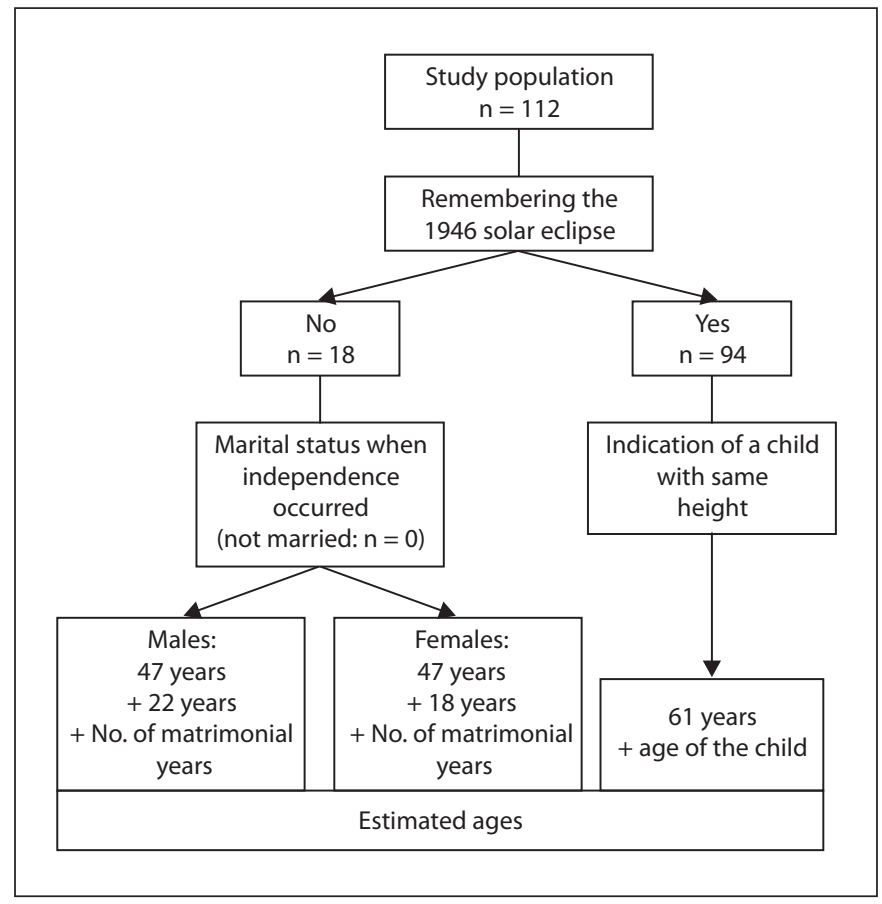

Fig. 1. Flow chart process of estimating the age of study participants, Benin, May 2008.

are approximately $>15,550$, that is $1.92 \%$ of the Cotonou population, $60.1 \%$ being females [6]. The city of Cotonou is divided into 2 parts (Cotonou I and II) by a laguna that crosses the city. Of the 13 districts that make up the city, Cotonou I has 8 (95/140 subdistricts) and Cotonou II has 5 districts. Cotonou I had the oldest urban development. Besides, it has an older population and was therefore chosen for this study.

We carried out a 1-stage cluster sampling, the sampling unit being the subdistricts. Using a door to door technique, people with at least a primary education, an administrative document that certifies their date of birth and who were at least 65 years of age were included in this study.

When the sample size is 99 subjects, a 2 -sided $95 \%$ confidence interval (CI) computed using the large sample normal approximation for an ICC based on 2 measurements will extend about 0.055 from the observed ICC when the expected ICC is 0.850 [7]. Calculations were done using the software NQuery Advisor ${ }^{\circledR} 7.0$ (Statistical Solutions, Saugus, Mass., USA). To take into account possible refusals to participate in the study (expected proportion of $20 \%$ ), the number of subjects required was estimated to be 119 .

Historical Events Used as Landmark

The historical events that served as markers were: the solar eclipse of 1946 covering the national territory and the date of independence of Dahomey (Benin) on August 1st 1960.

\section{Technical and Investigative Tool}

The questionnaire applied to estimate the age included the consecutive use of both historical landmarks (fig. 1). The investigator 


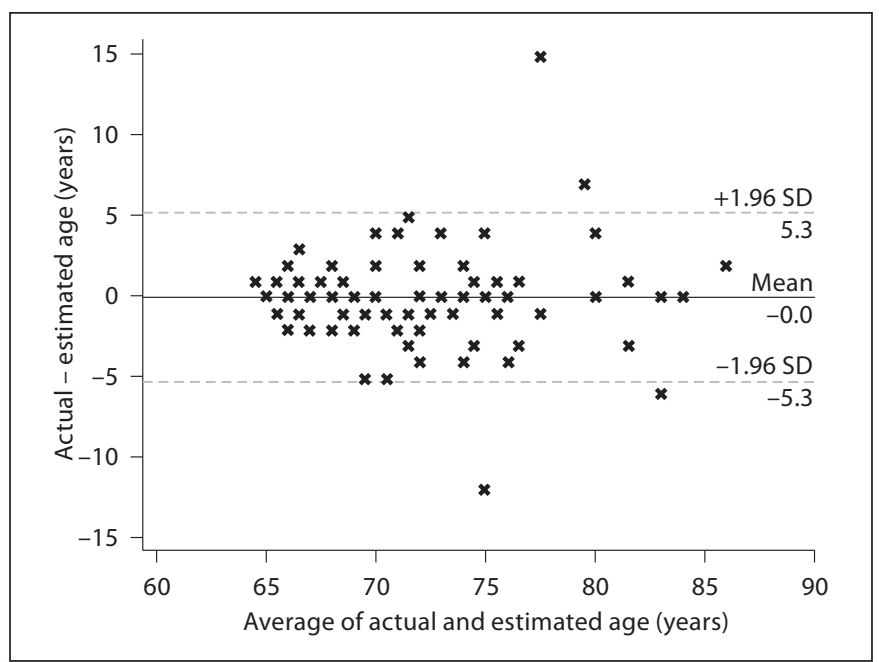

Fig. 2. Bland and Altman graph of agreement between actual and estimated age $(n=112)$, Benin, May 2008.

conducting the interview did not know the actual age of those surveyed, but made sure of the presence of an official record of the elderly's birth date. Before conducting this study, the questionnaire was tested to firstly guarantee the investigator's proper use of questions and flow chart for determining the age and secondly to ensure that the respondents understood the questions well.

First, the participants were asked if they remembered the solar eclipse of 1946. When the answer was yes, they were asked to indicate among a group of children the one who had approximately their height at the time of that event. To the age of the child, 61 years, which is the delay between the study period and 1946, were added to obtain an estimated age. However, to give more credit to the recollection of the event, any investigation which indexed a child $<5$ years was not accepted.

Secondly, if the participants did not remember the 1946 solar eclipse, they were asked about their marital status on August 1st 1960 (date of independence of the country). The average age at marriage for men in Benin is 22 years [8]. If the male subject was married or living as married, then 22 years, the number of matrimonial years at the independence date, and 47 years (period between the survey and the year of the independence of Dahomey) were added together to obtain an estimate of age. A similar approach was used in females, but the reference age for marriage or the beginning of living as married was set at 18 years [8].

\section{Statistical Analysis}

The data were recorded using Epi Info 2000 (v3.4.3) and analyzed with SPSS software v11.5 (SPSS Inc., Chicago, Ill., USA) and MedCalc v9 (Frank Schoonjans). The quantitative variables were expressed as averages, standard deviations and ranges. The qualitative variables were described as frequencies and percentages. Paired comparison of the average estimated age and actual age was performed by the paired Wilcoxon test. The agreement between estimated and actual age was assessed by the ICC [9] with a 95\% $\mathrm{CI}$ and with the Bland and Altman graphical representation [7].
Table 1. Demographic characteristics of subjects aged $\geq 65$ years in Cotonou whose age was estimated by the 2 historic landmarks, Benin, May 2008

\begin{tabular}{lcc}
\hline Characteristics & Number & $\%$ \\
\hline Sex & & \\
$\quad$ Male & 63 & 56.3 \\
$\quad$ Female & 49 & 43.7 \\
Marital status & & \\
$\quad$ Married/cohabitation & 78 & 69.6 \\
$\quad$ Separated/widow/widower & 31 & 27.7 \\
$\quad$ No response & 3 & 2.7 \\
Level of education & & \\
$\quad$ Primary & 64 & 57.1 \\
$\quad$ Secondary & 17 & 15.2 \\
$\quad$ Higher secondary & 20 & 17.9 \\
$\quad$ Superior & 8 & 7.1 \\
$\quad$ Primary but no further information & & \\
$\quad$ available & 3 & 2.7 \\
\hline
\end{tabular}

\section{Results}

\section{Characteristics of Respondents}

The study was proposed to 119 persons, but 7 (6\%) of them refused to participate. Thus 112 subjects aged $\geq 65$ were included in this study. Fifty-six percent of the subjects $(n=63)$ were male (table 1$) ; 69.6 \%$ of the subjects were either married or lived as married. Their level of education was mostly limited to primary school (57.1\%) and $15.2 \%$ of the people had completed the first level of secondary education.

Of all the subjects surveyed, $83.9 \%(\mathrm{n}=94)$ remembered the solar eclipse of 1946. Among the people who did not remember the eclipse ( $n=18,16.1 \%)$, all remembered the date of independence of Benin.

\section{Overall Concordance}

In the total study sample, the paired Wilcoxon test did not show any difference between the actual age (average $=70.9 \pm 5.3$, range $=65-87$ years) and the estimated age (70.9 \pm 5.2 , range $=64-86$ years), $\mathrm{p}=0.71$.

The ICC between the actual and estimated age by the use of historical landmarks was $0.87(95 \% \mathrm{CI}=0.81-0.91)$, i.e. an agreement that is considered as excellent. The Bland and Altman graph (fig. 2) was also in favour of a very satisfactory agreement between actual and estimated age. The average difference between actual and estimated age was 0 and there was no tendency to a variation of this difference by age (structure of the graph centered evenly around the average difference). Some points were 
outside the $95 \%$ CI of the estimated difference ( \pm 5 years) but were uncommon (4 points out of 112 observations).

The difference (in absolute value) between the estimated and actual age was 0 for 40 subjects (35.7\%), 1 or 2 years in $52(46.4 \%), 3$ or 4 years in $13(11.6 \%)$ and $>4$ years in $7(6.25 \%)$.

In the subgroup analyses, the ICC between actual and estimated age was also excellent for the patients whose age was estimated by using the independence of Dahomey in $1960(n=18, I C C=0.92,95 \%$ CI $=0.80-0.97)$ on the one hand and those whose age was estimated by using the solar eclipse of $1946(\mathrm{n}=94$, ICC $=0.84,95 \% \mathrm{CI}=0.77$ 0.89 ) on the other hand.

\section{Discussion}

Our study found that age estimation for people $\geq 65$ by using relevant historical events in Benin could be considered as a highly accurate method. The agreement between estimated and true age was shown to be excellent (ICC $=0.87,95 \% \mathrm{CI}=0.81-0.91)$. Our results have important implications as regards the epidemiological research in countries where there is a deficit of reliable and accessible administrative documentation. This timesaving method provides an accurate means to estimate age for research in which age is important to consider either as a major confounding factor or as a crucial inclusion criterion, like in epidemiological studies that focus on agerelated disorders.

A similar study [1] that also used historical landmarks for age estimation and had important correlations with the results from our study was conducted in Nigeria. However, the Nigerian study sample was smaller $(n=59$, 40-90 years of age) and recruited subjects from hospitals in contrast to the population-based nature of our study. From a methodological point of view, only the Spearman correlation coefficient was used in the Nigerian study. The result was probably biased for a high value because a correlation between 2 quantitative values (when they are supposed to measure the same phenomenon) is not sufficient to indicate good agreement. In other words, correlation between the 2 sets of data is necessary but not sufficient to demonstrate a satisfactory agreement. In this work the authors had not made any assessment of the concordance by either a numerical (ICC) or graphical method (Bland and Altman graph), which are appropriate when the measures to analyze are quantitative.

Based on sex and educational level, we acknowledge that our population is not representative of the whole el- derly population in Benin. The subjects included in our study had a better education level than the general population of Benin (11.4\% of the persons aged $\geq 60$ are educated [4]). Indeed our inclusion criteria requested subjects to have at least primary education. The minimum education level and the necessity of an official document certifying age might have facilitated the recruitment of only those who were from the upper social strata, who had an understanding of the research and an interest in our work. The possible impact of the education level on the results, while difficult to ascertain, has to be underlined. It is worth thinking that education could improve the remembering of historical dates, such as the independence of Dahomey. However, this landmark was used in $16 \%$ only and chosen because it was a popular event which was celebrated in the whole country and then left a deep impression on the populations.

Besides, people having birth certificates may recall events with their known age in mind, and thus the study sample may be better than the general population in identifying a child of their height at the time of the eclipse leading to a better accuracy of historical landmarks. It has to be acknowledged that today, people with more education may achieve a married or living-as-married status at an older age on average; this could also be true for people who are now aged $\geq 65$ years. This point could have induced underestimation in the age of the 18 people not remembering the solar eclipse. However, the ICC was also excellent with this landmark.

Also, the proportion of females in our study (45\%) is lower than expected ( $60 \%$ in Benin overall), which could also be related to the higher education level in men as compared to women. However, since the historical landmarks used for age estimation are part of the popular history of the country, we believe that the impact of having a higher education on our results is limited. Lastly in our method we decided that any investigation which indexed a child $<5$ years was not accepted. Although this procedure might lead to a better agreement, the impact on the results should be low.

Because of the nutritional transition, we can assume that the body size of the children of the 2000s is higher than that of children of the same age in the 1940s. A study reported an expected gradual decline in the prevalence of stunting between 1980 and 2020 in developing countries overall (from nearly $50 \%$ to $<20 \%$ ) and in Africa (approximately 39 to $32 \%$ ) [10]. Given the fact that the age estimation of the subjects $>65$ years in our study was made on the basis of the age of the child whose size was considered close to that at the time of independence of Benin, the 
transition population could be a potential source of underestimation of age in our study. However, it should be noted that given the excellent concordance yielded between actual and estimated age, this factor did not seem to have a significant impact on our estimates.

Of all respondents, it was observed that apart from those whose estimated age was equal to the actual age (absolute match), there were also cases whose age was estimated to be higher (overestimation) or lower (underestimation) than their actual age. However, for most, the difference was only 1 year. This result may be partly due to the fact that the dates of birth were estimated in years only, which easily leads to imprecision in the calculation between the date of survey and estimated date of birth (discretized quantitative variable). In terms of administrative use or as part of epidemiological studies, an overor underestimation of a year is acceptable.

The refusal to participate in the study was rare (6\%), and was mainly due to the lack of interest in participating in our study. This lower than expected (20\%) refusal rate allowed us to estimate ICC with better precision than we wished.

The development of simple readily usable tools in the epidemiological studies is essential. In this context a satisfactory estimate of the age of the subjects is very useful when official records are unavailable. A valid method such as the one used in our study allows a proper statisti- cal control of confusion bias related to age and accurate stratification of prevalence or incidence of diseases. This approach had been used in an epidemiological study on the cognitive subject, aged $\geq 65$ years and living in rural areas (Djidja - Benin) [5] conducted in 2007. The age of the subjects was estimated by the same historical events and had been successfully applied to $>500$ people without official documentation.

The development of similar tools in other parts of Africa and developing countries may help improve the quality of information collected and the validity of the findings.

Our results showed that historical landmarks can reliably estimate the age in subjects aged $\geq 65$ in Benin and are utilized within the framework of the government campaign under way in Benin which aims to establish and deliver birth certificates for persons who have not got any [2]. This approach is of paramount importance in reliably estimating the age in studies that address age-related disorders such as dementia.

\section{Acknowledgments}

We thank Devender Bhalla for the translation of the manuscript and Alfred Mondjannangni (Sainte Luce of Torri-Benin) who suggested us to use the solar eclipse of 1946 as historical landmark.

\section{References}

1 Ogunniyi A, Osuntokun BO: Determination of ages of elderly Nigerians through historical events: validation of Ajayi-Igun 1963 listing. West Afr J Med 1993;12:189-190.

2 République du Bénin: Audience foraine pour l'établissement d'un acte de naissance ou de jugement supplétif. Décret No 2006-318 du 10 juillet 2006.

3 Fratiglioni L: Epidemiology of Alzheimer's disease and current possibilities for prevention. Acta Neurol Scand Suppl 1996;165:3340.
4 Launer LJ, Andersen K, Dewey ME, et al: Rates and risk factors for dementia and Alzheimer's disease: results from EURODEM pooled analyses. EURODEM Incidence Research Group and Work Groups. European Studies of Dementia. Neurology 1999;52:7884.

5 Guerchet M, Houinato D, Paraiso MN, et al: Cognitive impairment and dementia in elderly people living in rural Benin, west Africa. Dement Geriatr Cogn Disord 2009;27: 34-41.

6 Institut National de la Statistique et de l'Analyse Économique (INSAE) Benin: Projection démographique et étude prospective de la demande sociale révisées 2002-2030. Mars 2009.
7 Bonett DG: Sample size requirements for estimating intraclass correlations with desired precision. Stat Med 2002;21:1331-1335.

8 Institut National de la Statistique et de l'Analyse Économique (INSAE) Benin: Enquête démographique et de santé 2001: nuptialité et exposition au risque de grossesse, 2002.

-9 Shrout PE, Fleiss JL: Intraclass correlations: uses in assessing rater reliability. Psychol Bull 1979;86:420-428.

10 De Onis M, Blossner M: The World Health Organization Global Database on Child Growth and Malnutrition: methodology and applications. Int J Epidemiol 2003;32:518526. 